\title{
Foreword II
}

\section{Andrea Martin}

While the music industry has evolved rapidly and beyond recognition since PRS came into being in 1914, the fundamental premise has not changed: there is no music industry without the songs, and there are no songs without the writers. And without copyright, writers cannot make a living or protect and control how their work is used. The primary purpose of copyright is to empower the creator.

While the views and analysis expressed in this book are entirely those of the author, we share a common view that everyone involved in the music industry benefits from a better understanding of their rights. Copyright is not something for someone else to care about, nor can decisions about its future be left purely to lawyers and academics.

In the digital marketplace, creators have greater opportunities than ever before to reach new audiences around the world, but those opportunities are accompanied by greater challenges in controlling and enforcing rights. Therefore, it is more important than ever to educate ourselves on the individual rights that arise from the creation of a work, how they can be used to create value and ultimately what can be done when those rights are infringed.

Copyright in the Music Industry is a very welcome addition to anyone's library. It deftly explains copyright in a simple and friendly tone, while imparting significant information. The author's experience of the music industry and in-depth knowledge and understanding of copyright and the wider legal framework are evident throughout.

Andrea Martin

CEO, PRS for Music 